\title{
CORRIGENDUM
}

\section{Phenotypic variability of CLDN14 mutations causing DFNB29 hearing loss in the Pakistani population}

Zil-e-Huma Bashir, Noreen Latief, Inna A Belyantseva, Farheena Iqbal, Sheikh Amer Riazuddin, Shaheen N Khan, Thomas B Friedman, Sheikh Riazuddin and Saima Riazuddin

Journal of Human Genetics (2013) 58, 641; doi:10.1038/jhg.2013.85

Correction to: Journal of Human Genetics (2013) 58, 102-108;

doi:10.1038/jhg.2012.143; published online 13 December 2012

The authors of the above paper noticed an error in publication (AOP and in February issue) in the list of authors. The fifth author Sheikh

Amer Riazuddin should have read S Amer Riazuddin. 